\title{
Privacy and Property in the Biobank Context
}

\author{
Lars Oystein Ursin
}

Published online: 27 August 2010

(C) The Author(s) 2010. This article is published with open access at Springerlink.com

\begin{abstract}
A research biobank is a collection of personal health and lifestyle information, including genetic samples of yet unknown but possibly large information potential about the participant. For the participants, the risk of taking part is not bodily harm but infringements of their privacy and the harmful consequences such infringements might have. But what do we mean by privacy? Which harms are we talking about? To address such questions we need to get a grip on what privacy is all about and aim for a fruitful perspective on the issues of property and privacy rights in the context of biobanking. This paper argues that the limits and handling of private matters is determined in specific social relations. The crucial point is thus to determine which information and activities are or are not the legitimate concern of others. Privacy and property rights should be seen as balanced by duties, that is as inherently relational interests extending into the public sphere, rather than to see these rights as the control of an object—for instance the participant's biobank material.
\end{abstract}

Keywords Privacy · Biobanking $\cdot$ Genetic samples · DNA

\section{Introduction}

What does research biobanking imply for the recruited participants? A research biobank is a collection of quite personal health and lifestyle information and of genetic samples of yet unknown but possibly large information potential about the participant. Are large-scale public biobank projects involving a substantial part of a country's population a possible colonization by the State of the private sphere of its

L. O. Ursin $(\bowtie)$

Department of Philosophy, Norwegian University of Science and Technology,

NTNU-Trondheim, 7491 Trondheim, Norway

e-mail: lars.ursin@hf.ntnu.no 
citizens? Is this compatible with the basic ideals of individual freedom in Western liberal societies? Or is it, advertently or inadvertently, a return to the mindset of totalitarian regimes?

Does commercial biobanking, on the other hand, imply a massive commodification of the participants in involving the transaction of one's DNA in return for some kind of sharing of the benefits of the biobank research? And if no policy of benefit sharing is involved, is commercial biobanking a massive exploitation of the research participants? Does the requirement of informed consent by the participants alter any of these concerns? Does the voluntariness of commodification or of giving up your privacy erase any questions of the ethical legitimacy of biobanking? Biobank research is research on information concerning and tissue samples from the participants. For the participants, the risk of taking part is not bodily harm but infringements of their privacy and the harmful consequences such infringements might have. But what does this mean? What do we mean by privacy? Which harms are we talking about?

In order to address these questions we need to get a grip on what privacy is all about, and aim for a fruitful perspective on the issues of property and privacy rights in the context of biobanking. In this paper, I argue that the limits and handling of private matters is determined in specific social relations. The crucial point is thus to determine which information and activities are or are not the legitimate concern of others. Privacy and property rights should be seen as balanced by duties, that is as inherently relational interests extending into the public sphere, rather than to see these rights as the control of an object-for instance the participant's biobank material.

\section{Privacy as Control}

What is privacy? What is a right to privacy? After an extensive discussion of different attempts at defining a right to privacy, Adam Moore settles for this one: "A right to privacy is a right to control access to and uses of-places, bodies, and personal information" (Moore 2008, p. 421). Moore's view is that privacy is essentially a normative concept. For him, this means that the privacy of an individual is to be understood in terms of rights of privacy granted the individual. According to Moore, privacy is about access and the ability of the individual to control access: "When an individual restricts access to himself and to personal information, we may say that a condition of privacy obtains" (p. 421). The right of the individual to control access is consequently the crucial normative and descriptive question of privacy identification.

To define privacy in terms of control does, however, seem to get things wrong. As pointed out by William Parent: if someone voluntarily chooses to divulge very personal information to others, this would amount to giving up privacy rather than to exercise privacy control (Parent 1983, p. 273). Moore argues against Parent by asserting that just as one freely can limit one's freedom, one can in a controlled way limit one's control. But the crucial point here is that Moore's account of privacy is descriptively inaccurate. A person can autonomously decide to give up his 
autonomy. He voluntarily decides to become my slave. But he will then no longer lead an autonomous life, since I decide what he will do (see, for example, Ursin 2009). Likewise, a person can quite independently decide to give up her privacy. She voluntarily decides to install webcams in every room of her house. She will then simply no longer lead a home life of privacy, since everybody is invited to watch her.

This brings out two important aspects of the notion of privacy as a matter of rights - and of duties. Firstly, it points to the connection between intentionality and control in matters of privacy. I enjoy privacy in my flat even if it is possible to peek in my windows with a lot of equipment and effort. But if I broadcast my home life I enjoy no privacy anymore. It is the intention and reasonable effort on my part to control access to my private sphere that is crucial, not that the walls of my private sphere are actually impenetrable. Thus my privacy is part of a social relation, rather than exempt from social relations: I do not have to make sure that you are unable to read my diary in order for it to be private, I just have to make it clear that you are not supposed to read it and trust you not to.

Secondly, the notion of privacy refers to certain facts about and acts committed by an individual. Which facts and acts those are is not, however, decided by that individual alone. The right to be left alone and to keep information out of the public eye is not just a right but also a duty of the individual. What is and is not a duty to keep to oneself is a matter of context and culture. How much clothing a woman must wear on a hot summer day in order to be decent depends on whether she is at the beach or in court, and on whether she is in Sweden or in Saudi-Arabia. Participants in reality shows like Big Brother might be considered indecent and vulgar because they reveal too much of what is considered private matters, and consequently should be kept to oneself. Moreover, the blurring of the line between the public and the private is, as Richard Sennett argues in The Fall of Public Man (1977), no less than undermining the basis for civilized societies based on joint efforts to pursue political interests in a principled way rather than as group interests based on close relations of friendship.

If privacy was just about the ability to keep things to oneself, that would mean that once these things are known by others they are no longer private. This view is actually endorsed by Moore: "by yielding control to others the condition of privacy is diminished or no longer obtains" (Moore 2008, p. 415). As the condition of privacy is socially determined, the yielding of control to others of matters considered private must lead to a collective change in the perception of these matters for them to lose their privacy status. When Craig Venter in 2008 published his genome on the Internet he gave up his genetic privacy. In doing so, he might, however, induce a change of perception concerning the private character of genetic information. Maybe the harm of making known your genome is not so big after all? Maybe we were wrong in regarding genetic information as necessarily sensitive and thus something the individual should strive to keep for himself?

A sign of such a cultural change concerning the view of genetic privacy is the Personal Genome Project of Harvard Medical School (http://www.personalgenomes. org/). The Personal Genome Project opened itself up to the public on April 25, 2009 and aims to sign up 100,000 volunteers for the world's first publicly accessible 
genome database. The participants of the Personal Genome Project will not have their names published. But their genomic information, complete medical histories, and even their photos will be made public. In an article defending the ethical policy of the Personal Genome Project, Lunshof et al. states that

volunteers consent to unrestricted re-disclosure of data originating from a confidential relationship, namely their health records, and to unrestricted disclosure of information that emerges from any future research on their genotype-phenotype data set, the information content of which cannot be predicted. No promises of anonymity, privacy or confidentiality are made. The leading moral principle is veracity - telling the truth — which should precede autonomy (Lunshof et al. 2008, p. 409).

If genetic privacy is practically impossible to uphold in biobank research projects, as argued by Lunshof et al., the freedom to divulge any genetic information about yourself should be morally approved of in society in order to make legitimate recruitment to biobank research possible. Thus the condition that "by yielding control to others the condition of privacy is diminished or no longer obtains" is granted by a normative change in society on the nature of personal genetic/genomic information.

\section{Confidentiality and Relational Privacy}

In addition to the private thoughts and secluded life of the individual, matters of privacy comprise of shared information and relations of confidentiality. The personal information contained in biobanks is traditionally regarded as confidential information. The use of this information is regulated by the continuous consent of the individual and the decisions of the researchers, ethics committees and governmental bodies.

What is the relationship between privacy and confidentiality? On the one hand, confidentiality could be seen as just a special case of privacy protection, in which the duties of the one who has gained access to personal information about another person has a clear duty not to pass on the information to outsiders, or use it for other ends than the one agreed upon. On the other hand, confidentiality could be viewed as quite different from privacy, in making it an ethical and even legal duty of the one who has gained access to keep the information confidential-even if this could harm persons outside of the relation of confidentiality. This difference will be elucidated in this section by bringing in the notion of relational privacy.

The notion of confidentiality shows in a good way the social nature of private information, but in a poor way the normativity of privacy relations. On the one hand, the confidentiality relation lacks the necessary nuances of normativity concerning the use of information inside of the relation of shared information. This is pointed out by Graeme Laurie in saying that

to the extent that the duty of confidentiality is solely concerned with keeping confidential information out of the public sphere, it says nothing about the 
duties that might be owed within the confidential relationship towards the subjects of the information so as to ensure, inter alia, that the personal interests of these individuals are not treated with a lack of respect by unwarranted uses of information with regard to the subjects themselves (Laurie 2002, p. 3).

A patient's or a research participant's right not to know certain genetic risk information is of special concern for Laurie here.

On the other hand, the confidentiality relation lacks the necessary nuances of normativity concerning the use of information outside of the relation of shared information. Again this is pointed out by Laurie:

Clearly, although a health care professional owes a duty to respect a patient's genetic information as confidential, conflicts can arise about access to that information and its control, and the problem becomes whether the health care professional would ever be justified legally ethically or professionally in disclosing such confidential data. So, how do the rules relating to confidentiality apply to genetic information, especially when one considers that third parties such as relatives or the state can claim a significant interest in many forms of this information (p. 230)?

In order to see clearly the normative nuances concerning the use of information inside and outside of the relation of shared information we should have a relational understanding of privacy. Instead of trying to identify what kinds of information the individual has a right to control access to, or to make detailed contracts of confidentiality, we should view my right to privacy as essentially dependent on your corresponding duty to protect my privacy. To protect my privacy implies for you a duty not to obtain or spread information about me or the group to which I belong that is clearly not someone else's business.

The limits of my private matters are here explicitly determined by normative assessments of both myself and others. This view is reflected in Judith DeCew's definition of the private as comprising of "whatever types of information and activities are not, according to a reasonable person in normal circumstances, the legitimate concern of others" (DeCew 1997, p. 58). This perspective makes clear the connection between my right to privacy and the duty of others to protect this right. It also opens up for a clear view of the connection between the right to privacy of the individual, and the perfect or imperfect duty to disclose information for the common good or other interests.

Ferdinand Schoeman has criticized making the absence of other's concern a criterion of the private in a way parallel to the criticism raised above to making control the criterion of the private:

Such a criterion, plausible at first, is subject to the following difficulty. Whatever one might claim as falling within his or her private realm could be reclassified on the basis of others manipulating the situation so that they have a stake in that state of affairs. ... Few would be tempted to think that such practices deprive these domains of life of their private character (Schoeman 1984, pp. 7-8). 
Schoeman's objection emphasizes that the crucial question raised by the view that the limits and handling of private matters is determined in specific social relations, is how to determine which information and activities are or are not the legitimate concern of others (see, for example, Ursin 2008). In order to explore this further we should therefore have a look at the privacy issues in a specific contextin this paper, the context of participation in commercialized biobanking.

\section{The Ethical Challenges of Commercial Biobanking}

For more than a century, tissue samples have been collected for research and clinical purposes. Several hundred millions of samples are presently stored at hospitals world wide. These tissue banks are mainly publicly owned. Some clinical genomics companies also operate their own bio-repositories, or gather genetic information from participating patients and from a few of the many publicly owned tissue banks, notably from university hospital collections.

The scientifically and ethically most promising way to do genomics research might, however, be in the form of public-private collaboration on the use of public population research biobanks. Such biobanks offer ample opportunities for linking genealogical, environmental and lifestyle information provided by the participants with public medical registers. The legal and ethical aspects are also ideally "taken care of" in terms of an exhaustive consent given by the participants-exhausting the possible ethical and legal problems that might hamper research and public relations. As noted by Graham Lewis: "The several public collections or biobanks already established, or in the process of being established, provide another, and perhaps the most significant, avenue for commercial exploration of genetic data in the future" (Lewis 2004, p. 193).

The potential of genomics to benefit public health care in terms of more precise prevention and treatment of diseases has raised the interest of governments to establish or prioritize existing large population biobanks well suited for genetic research. Research in genetic epidemiology and pharmacogenomics might be of great benefit for the cost of patient treatment, the precision of disease prevention and the effectiveness of prescribed drugs. Population biobanks might also be vital to the isolation of disease genes in order to develop new drugs, and consequently of particular interest to the pharmaceutical industry. In this way, governments have an interest in establishing population biobanks both in order to save money in making health care treatment more targeted and efficient, as well as creating new jobs in arranging for local biotechnological companies or branches to emerge.

Research biobanks are currently set up by public institutions and private companies to explore the complex interrelations between genotypic and phenotypic elements leading to disease. But biobanking is about actually doing biobank research. It is about putting the biobank material to good use and not just about making a collection. Participants and researchers alike take part in order to make the creation of new medical knowledge, therapies and drugs possible. A prerequisite for accomplishing this, it is argued, is state-industry collaboration. The task of drug development, for instance, has internationally been given to the pharmaceutical 
industry, which consequently has the economic and scientific resources necessary for going from "genes to drugs", to use the phrase of deCODE genetics (http://www.decodeme.com).

The view that biobank research is of great ethical, scientific and economic significance has, to take a specific example from the Scandinavian context, recently been voiced by important Norwegian ethicists and researchers. They argue that Norwegians have an economic interest in pursuing biobank research and, moreover, even have an ethical obligation to establish biobanks and do biobank research to the health benefit of the global community. There is a vision of the need for collective action for the manifold advantage of all, and in order to benefit from the potential of existing Norwegian biobanks and health registers, and to benefit from the relative ease of gathering Norwegians to take part in new research biobanks in the future.

In Norway, a new Health Research Act was passed in the Norwegian Parliament in June 2008 to replace the Norwegian Biobank Act. The aim of the new legislation is to remove bureaucratic obstacles for health research, by making the application and approval process of new health research projects better and less cumbersome for researchers. The measures of the new Act includes opening up for the use of broad consent, where, for instance, biobank research participants consent to take part in future and yet unspecified research projects carried out using their biobank material.

Which political and ethical challenges does commercialization imply? In the case of public research biobanks like the Norwegian biobank HUNT (http://www. ntnu.no/hunt/english), which is totally dependent on the voluntary participation of the invited citizens, trust is vital. Erosion of trust threatens to disrupt the recruitment of new participants and make people already enrolled decide to leave the biobank. How does trust go together with commercialization for participants? In a focus group study with HUNT participants, it was found that commercialization was indeed seen as the main threat to the trustworthiness of HUNT (see, for example, Skolbekken et al. 2005). Commercialization was seen as potentially introducing other aims than those that motivated the participants to take part: while the participants described their motivation to take part in terms of a contribution to improvements in health care based on principles of justice, beneficence and solidarity, commercialization was seen as potentially leading to research guided by might rather than right, to the benefit of the wealthy rather than the needy. However, if commercially funded research was approved of by local research ethics committees and came in addition to, rather than instead of, publicly funded research, it was not seen as necessarily in conflict with the trustworthiness of HUNT.

This nuance in the public assessment of commercialization of biobank research is found in several studies in different countries, for instance in Sweden:

Patients may voice strong concern about contributing to research sponsored by private companies, as opposed to research sponsored by foundations, but in a study of actual donors, only $1 \%$ refused to allow their tissue to be used for commercial research. In our study, a minority of the respondents said that their decision to donate a sample would be influenced by the financial support for the research. Most chose to delegate this judgment to the ethics committee. Another Swedish study confirms that the majority of the public are willing to 
delegate some decisions on the use of their biological samples to the ethics committees (Kettis-Lindblad et al. 2006, p. 437).

Biobank participants contribute on the premise that research is done which really does benefit the common good. Biobank research should aim for external justice in avoiding a bias of interest in diseases affecting the rich rather than the poor. On the other hand, as a matter of internal justice, no party involved in the biobank research process should be exploited by another.

The concern for internal justice in the research process is expressed by biobank participants in opposing the idea of commercial companies making profits from the participants' voluntary and unpaid contributions to the biobank. Their contributions are both in the form of research participation and in paying taxes for financing the biobank as a public enterprise. The industry is in short getting something for nothing, while the participants are getting nothing for something. Still, participants think that denying the pharmaceutical industry access to data from public biobanks means that a lot of potentially useful research simply will not be done.

This concern questions the traditional way, especially in Britain, of conceiving contributions to health care and medical research in terms of the so-called gift relationship. In his classical work from 1970, Richard Titmuss argued that blood donations should be treated as gifts rather than commodities, as commercialization of blood donations would have adverse effects on solidarity and altruism (Titmuss 1970/1997). But, in order to involve commercial research in a just way the gift model is seen as inappropriate-both in the case of a purely commercial biobank like the one of deCODE, and in the case of a planned public/private collaboration like the one of HUNT Biosciences. Thus the notion of benefit-sharing between the profit-making party and the non-profit party has been suggested. In their discussion of the views of potential participants in the planned biobank project Generation Scotland, Haddow and colleagues argues that some kind of benefit-sharing should be introduced:

Whilst, historically, medical research and therapies have relied on the 'gift' model, this might not be appropriate in the present context as it no longer accurately reflects public attitudes towards the commercial realities of the research enterprise. Our research indicates that elements of the current approach are being challenged and that corrective action is required. The challenges include: (1) the expanding phenomenon of patient and advocacy groups which seek a more active role in genetic research, (2) the growing perception of injustice with respect to an institutional framework which, on the one hand, promotes participant altruism, and yet, on the other hand, sanctions third party commercialisation and private property rights, (3) the perceived inadequacy of regulatory control mechanisms which make no mention of 'property', and finally, (4) the suggestion that commercialisation practices can be 'tolerated' in certain circumstances (Haddow et al. 2007, p. 281).

The problem with the perspectives of gifting and altruism is that they deflect attention away from the participants' concerns about injustice in the research enterprise, and obstruct a discussion of this aspect of commercialization. The 
rhetoric of altruism and gift-giving makes the act of contributing tissue and information belong to a different sphere than the economy of commercial exploitation of the same tissue and information.

In order to address these concerns about fairness, the perspective of private property can be introduced on the side of participants as well, in an attempt to achieve some kind of symmetrical relation between donors and the industry. Introducing property rights for participants holds out the promise of tearing down the glass wall between participants and pharmaceutical companies which is seen to legitimize an exploitation of research participants by the industry. The paradigmatic case in this respect is the case of John Moore, who in 1976 underwent treatment for his leukemia when his doctor decided to create a cell line from his spleen. The cell line was successfully patented and became quite profitable for Mr. Moore's doctor. Mr. Moore subsequently took the case to court to claim the property right to the cell line in order to gain part of the profit. The California Supreme Court, however, decided that Mr. Moore's spleen simply was not his property, while the cell line clearly was the property of the university holding the patent rights [Moore $v$. Regents of the University of California, 793 p.2d 479 (Cal. 1990)]. The ruling of the court was in line with the principle that "anything under the sun made by man" is patentable-except man himself. Judging by this principle, it was clear that no-one holds any patent rights to their own body or body parts, while anything made from the natural resource of human tissue in principle is patentable.

Research participants could, however, be equipped with property rights different from patent rights that could enable the individual to re-negotiate the contract with the research institution to include benefit-sharing. The meaning and importance of the informed consent form to be signed by biobank participants would in that case all of a sudden be clear: instead of being an ugly duckling - a confusing statement of autonomy and altruism, dependent on the vagueness of trust-it grows into the swan of a real transparent contract between the stakeholders of biobank research (Skolbekken et al. 2005, p. 345).

The perspective of tissue as private property has few ethical and political problems with commercial biobanking. Commercial biobanking seems to suit the enterprising individual, who worries productively and personally takes charge of his or her own biobank material and his or her health and body and carefully looks after it. DeCODEme, for instance, offers "a genetic health scan. Getting to know your personal genome will empower you and provide you with a road map to improve your health" (http://www.decodeme.com, accessed May 29, 2009).

\section{The Rights and Duties of Privacy}

However, in addressing the question of the ethical and political challenges of commercial biobanking, it is important to distinguish between commercialization and privatization. As pointed out by research participants: their worry concerning commercialization is the introduction of other aims than the common good and the possibility of losing control of the research, rather than the prospect of research conducted by private companies as such. A HUNT participant puts it this way: 
As we're living in a well-organized society with laws and regulations and circulars, I'm pretty confident that [the samples] won't be abused in the society we have at the present. And will continue to have-in my day, anyhow. It is however hard to tell anything about the society of the future, because it [the society] seems to be governed pretty much by economics, capital and those kinds of values (Skolbekken et al. 2005).

For a private company it might be more profitable to develop expensive preventive drugs aimed to be used by large risk groups for decades, rather than cheap and effective drugs which do away with a problem once and for all. And, as remarked by Ron Bouchard and Trudo Lemmens: "[O]nce the marketplace has control over the funding, development and licensure of biomedical products, it can shape human needs primarily toward products that the market itself can develop" (Bouchard and Lemmens 2008, p. 32).

And, if public research is governed more and more in the line of satisfying a market in terms of output-in terms of published articles on new risk factors, initiating research which attracts external funding, keeping knowledge out of the public domain by the use of patenting, creating spin-out companies-then the voiced worry concerning commercialization affects public research as well as private. In this perspective, both private and public research can be termed commercial. This leads to a set of fundamental questions concerning the governmental role towards public health, as pointed out by Bouchard and Lemmens: "Is it the primary function of public health agencies to protect the public? Is it to stimulate the economy through biomedical research commercialization? And, if both, where does the balance lie on a scale of public to private concerns?" (2008, p. 35, emphasis added).

Moreover, if group and external factors are de-emphasized, while factors dependent on lifestyle and personal choice is emphasized, such that individual citizens are seen as governors of their own health, the task of both private and public biobank research will be to map the terrain of risk information and preventive measures and "empower" the citizens to maneuver in this terrain in the spirit of deCODEme.

Another useful distinction when addressing the ethical question of commercialization in this field is between the concepts of persons and things, or between persons and property. The distinction between a person and a thing is known in legal terms at least since the Roman Law, but is argued to take on a special significance in capitalist economy, as Klaus Høyer argues with the help of Thomas Haskell:

For markets to emerge, people had to be able to sell their labour as a commodity. Accordingly, [Thomas Haskell] argues, the emergence of a capitalist mode of production is connected to the abolition of slavery. The stabilized legitimacy of the alienation of labour is thus intertwined with the emerging inalienability of the body. Besides, in a capitalist economy, people must serve not only as labourers but also as consumers, the latter being incompatible with a slave-based economy. The double function of the worker as labour reserve and consumer generates overall more wealth for the capitalist entrepreneur. My claim is that, in the course of this historical process, persons as bodily agents and commodities as things became naturally 
opposing poles in an increasingly dominant moral thought figure posing one as the antithesis of the other (Hoeyer 2007, p. 330).

The moral distinction between persons and things makes for strong reactions to transgressions of this divide. Commodification transgresses the distinction between person and thing and is generally regarded as incompatible with human dignity. This is explicitly stated for instance in the Formula of Humanity of Kant: the version of the Categorical Imperative that demands that we treat each individual as an end in him/herself and never merely as a means.

The installment of property rights as the way to tackle political and ethical challenges of commercialization is controversial because it is open to accusations of commodification. We can bring this out by returning to the Moore case: granting property rights of tissue to Mr. Moore or to biobank participants requires the bold step of blurring the line between a person and an object. The California Supreme Court argued accordingly that granting Mr. Moore property rights to his spleen would amount to making commodification of the human body legitimate.

The gift model promoted by Titmuss was an attempt to block commodification of the human body to avoid moral exploitation. The principle that all participation in medical research should be voluntary can also be invoked to question the legitimacy of granting research participants property rights - if it leads to participation being motivated by economic pressure. A problem with the gift model is, however, that giving a gift implies ownership. You cannot give what you do not own. In this way, the very idea of gift-giving presupposes the perspective of individual property rights rather than presenting an alternative view.

The biobank research enterprise does, however, by its very nature challenge the strict distinction between person and thing, because it is not obvious how the blood donated to a biobank fit into either of these categories. The blood provided to a biobank is more than just a thing for the participants: it contains their genes and can be linked to other information provided by the participants or coming from public registers. In a study in Sweden, biobank participants expressed ambiguous views of the nature of their contributed blood sample. The overriding majority, however, thought that getting paid to donate tissue samples was unethical. Interestingly, the participants saw the act of giving without getting paid as making sure that "the recipient ... feel certain obligations" (Hoeyer 2005, p. 57).

Identifying the nature of these obligations seems to be the crux of the matter here. To view participants' interests in terms of individual property rights obscure rather than clarify the challenges of commercialization. It makes us ask who actually owns genetic material, for instance, which imposes a false dilemma on us: Does the genetic material belong to the person it stems from, and if it does not, does this make the human body into a natural resource, to be harvested by a researcher like in the Moore case? Does it make the human body into a public resource, making it a property of the State, grounding, for instance, a legal duty of taking part in national or regional biobank projects like HUNT? Neither talking about a person owning her own body nor talking about the State owning a person's body seems to provide us with an adequate answer to the legitimate concerns of the participants' regarding the governance of biobanking. 
If privacy is viewed as a private matter of the individual, the primary protection of privacy in the context of biobanking is the principle of voluntary participation. The requirement of informed consent acts consequently as protection of privacy by setting up a barrier against having to give up privacy. But the notion of privacy should be relevant to biobanking. Privacy should therefore be something more than a negative right. As pointed out by Laurie: "A serious limitation on any concept of privacy is the fact that, as a right, it is negative in nature. ... To this extent, privacy suffers from limitations similar to those that afflict the principle of respect for autonomy; namely, it does not provide for any continuing control over personal matters once they enter the public sphere" (Laurie 2002, p. 300). This suggests an emphasis on the interests of the participants, as individuals and as members of a group. Rather than to see privacy and property rights as the control of an object (or of a subject-oneself extended into the biobank), we should see these rights as balanced by duties, that is as inherently relational interests extending into the public sphere.

The ambiguous nature of biobank material invites us to think in terms of managing the duties and rights involved in biobank research with the aim of better public health. Such management demand a kind of co-ownership of biobank material, for instance in the form of establishing charitable trusts, as the one proposed by David Winickoff, where donors are supposed to own the contributed material in the sense of having an individual right of opting out, and a collective right to decide on the use of the material-including outside use, for instance by the industry. According to Winickoff, his "Biotrust model" aims to contribute to the

ongoing project to construct a genomic governance that acceptably orders the interface between public and private [that] reconceive genomics as an enterprise driven not by profit, but by collective political will. The Biotrust Model (...) seeks the elusive balance between respecting the dignity of human persons and generating public value, a balance that has been unsettled by the new modalities of biological science, technology, and property. In order to accomplish these tasks, it constructs a hybrid legal identity for genomic resources, one that stakes out a position between personhood and property, gift and commodity, group and individual, public and private. Its merit, if it has any, will be measured not by its theoretical novelty, but by its practical ability to open pathways of democratic governance through complex technoscientific endeavors (Winickoff and Neumann 2005, pp. 18-19).

One aspect of addressing the ethical and political challenges of commercial biobanking is thus to find a way to avoid both economic and moral exploitation of research participants in accomplishing the common goal of improved health care. If tackled in terms of property rights, these rights should be subject to conditions both protecting the privacy and dignity of the participants and the interest in making biobank research feasible. We should not think of the issues of privacy and property as a simple conflict between individuals' interest in privacy and society's interest in doing research. The issue of property rights brought forth by commercialized biobanking shows that there is a considerable public interest in protecting the privacy of individuals to protect their bodily integrity and to promote the 
recognition of proper respectfulness of each individual as a person. The individuals, on their part, have a considerable interest in enabling research.

But is not this way of thinking about privacy at odds with fundamental principles of liberal societies? Is it not so that the right to privacy is the yardstick of the degree of civilization in a society? Is not the privacy granted the individual a right more fundamental than individual autonomy and liberty, in being a presupposition for both? The answer to this is that it is the legitimacy of privacy claims which has to be assessed in their specific relations, in a precise manner. Indeed, sometimes privacy is prior to liberty, in cases where the individual is prepared to waive her right to privacy but is denied this by ethical or legal barriers.

The dependence of liberty on privacy is a contingent matter: while totalitarian regimes gave you a reason to have privacy concerning religious views for instance, liberal societies should have reached the state of making privacy unnecessary because of pervasive tolerance. In the same way, the need for genetic privacy will depend on the social and economic sanctions present in society regarding genetic variations and disease traits. Privacy is not just about separateness and control, but also about as integrity and respect for persons. The right to privacy is the fundamental right to be recognised as a person, and not as an object and a mere means for the ends of others. In this sense, the right to privacy is quite fundamental and inalienable.

Open Access This article is distributed under the terms of the Creative Commons Attribution Noncommercial License which permits any noncommercial use, distribution, and reproduction in any medium, provided the original author(s) and source are credited.

\section{References}

Bouchard, R. A., \& Lemmens, T. (2008). Privatizing biomedical research—a "third way". Nature Biotechnology, 26(1), 31-36.

DeCew, J. (1997). In pursuit of privacy: law, ethics and the rise of technology. Cornell: Cornell University Press.

Haddow, G., Laurie, G., Cunningham-Burley, S., \& Hunter, K. G. (2007). Tackling community concerns about commercialisation and genetic research: a modest interdisciplinary proposal. Social Science and Medicine, 64(2), 272-282.

Hoeyer, K. (2005). The role of ethics in commercial genetic research: notes on the notion of commodification. Medical Antropology, 24, 45-70.

Hoeyer, K. (2007). Person, patent and property: a critique of the commodification hypothesis. BioSocieties, 2, 327-348.

Kettis-Lindblad, A., Ring, L., Vibert, E., \& Hansson, M. G. (2006). Genetic research and donation of tissue samples to biobanks. What do potential sample donors in the Swedish general public think? The European Journal of Public Health, 16(4), 433-440.

Laurie, G. (2002). Genetic privacy: a challenge to medico-legal norms. Cambridge: Cambridge University Press.

Lewis, G. (2004). Tissue collection and the pharmaceutical industry. In R. Tutton \& O. Corrigan (Eds.), Genetic databases (pp. 181-202). New York: Routledge.

Lunshof, J. E., Chadwick, R., Vorhaus, D. B., \& Church, G. M. (2008). From genetic privacy to open consent. Nature Reviews Genetics, 9, 406-411.

Moore, A. (2008). Defining privacy. Journal of Social Philosophy, 39(3), 411-428.

Parent, W. A. (1983). Privacy, morality, and the law. Philosophy \& Public Affairs, 12(4), 269-288. 
Schoeman, F. (1984). Privacy: philosophical dimensions of the literature. In F. Schoeman (Ed.), Philosophical dimensions of privacy: an anthology (pp. 1-33). Cambridge: Cambridge University Press.

Sennett, R. (1977). The fall of public man. New York: Penguin Books.

Skolbekken, J. A., Ursin, L. Ø., Solberg, B., Ytterhus, B., \& Christensen, E. (2005). Not worth the paper it's written on? Critical Public Health, 15(4), 335-347.

Titmuss, R. (1970/1997). The gift relationship: from human blood to social policy. New York: New Press. Ursin, L. Ø. (2008). Biobank research and the right to privacy. Theoretical Medicine and Bioethics, 29, 267-285.

Ursin, L. Ø. (2009). Personal autonomy and informed consent. Medicine, Health Care and Philosophy, 12(1), 17-24.

Winickoff, D. E., \& Neumann, L. B. (2005). Towards a social contract for genomics: property and the public in the "biotrust" model. Genomics, Society and Policy, 1(3), 8-21. 